\title{
Long-Term Neurocognitive Function of Pediatric Patients with Severe Combined Immune Deficiency (SCID): Pre- and Post-Hematopoietic Stem Cell Transplant (HSCT)
}

\author{
Malinda Lin • Karen Epport • Colleen Azen • \\ Robertson Parkman • Donald B. Kohn • Ami J. Shah
}

Received: 19 June 2008 / Accepted: 25 August 2008 /Published online: 20 September 2008

(C) Springer Science + Business Media, LLC 2008

\begin{abstract}
Background Hematopoietic stem cell transplantation (HSCT) is the only cure for patients with severe combined immunodeficiency (SCID). The purpose of this study was to evaluate long-term neurodevelopment of patients with SCID following myeloablative chemotherapy and HSCT. Materials and Methods Sixteen pediatric patients diagnosed with SCID were tested using the Bayley Scales of Infant Development and the validated Vineland Adaptive Behavior Scales (VABS) pre- and 1-year post-HSCT. Three years post-HSCT, there were 11 patients available for testing and four patients available 5 years post-HSCT. Patients greater than 3 years of age were administered the Wechsler Preschool and Primary Scale of Intelligence. Both raw scores and scaled scores were analyzed.

Results There was a significant decrease 1 year post-HSCT in the Bayley Mental Developmental Index (MDI) [92.5 (pre) vs. 70.81 (1 year post), $p<0.0001]$ and the VABS
\end{abstract}

M. Lin · R. Parkman • D. B. Kohn · A. J. Shah

Department of Pediatrics, Keck School of Medicine,

Los Angeles, CA, USA

\section{K. Epport · C. Azen}

General Clinical Research Center,

Children's Hospital Los Angeles,

Los Angeles, CA, USA

\section{R. Parkman • D. B. Kohn • A. J. Shah $(\bowtie)$}

Division of Research Immunology/Bone Marrow Transplantation, Children's Hospital Los Angeles,

4650 Sunset Boulevard, MS \#62,

Los Angeles, CA 90027, USA

e-mail: Ashah@chla.usc.edu

R. Parkman • D. B. Kohn • A. J. Shah

The Saban Research Institute of Children's Hospital Los Angeles, Los Angeles, CA, USA
[99.73 (pre) vs. 79.87 ( 1 year post), $p=<0.0001]$. There was a significant decrease over time in the MDI $[95.00$ (pre) vs. 72.64 ( 1 year post) vs. 71.82 ( 3 years post), $p<0.0001]$, but no significant change between 1 and 3 years post-HSCT. There was no change in the Bayley Psychomotor Development Scale (PDI) $[82.4$ (pre) vs. 84.8 (1 year post), $p=$ 0.68]. The PDI scores decreased over time [86.29 (pre) vs. 86 (1 year post) vs. 74.14 (3 years post), $p=0.045]$. Although there was a decrease in scaled scores, there was not a loss of skills. Analysis of raw scores showed that there was an increase in the raw test scores, which indicated that these children acquired developmental skills, but at a slower rate than normal infants and toddlers. Younger children had a more significant decrease in adaptive scores compared with older children.

Conclusions These findings may reflect the effects of the isolation and prolonged hospitalization that characterizes the immediate post-transplant period. Patients miss out on social interactions and learning opportunities that normally occur at their respective stages of development. These restrictions keep patients from acquiring developmentally appropriate cognitive skills as well as gross and fine motor developmental milestones. Longitudinal follow-up will be important to quantify acquisition of skills.

Keywords SCID - Hematopoietic stem cell transplants . long-term outcomes $\cdot$ development

Severe combined immunodeficiency (SCID) is a fatal disorder that is characterized by defects in both cellular and humoral immunity [1]. SCID occurs with an estimated frequency of one in 75,000 births [2]. Patients present early in life with a variety of opportunistic infections. Common clinical manifestations include failure to thrive, candidiasis, diarrhea, and pneumonia [3]. Hematopoietic stem cell 
transplantation (HSCT) offered the first cure for this disease in 1968 [4]. Since then, HSCT is the treatment of choice for patients with SCID.

Previous studies have yielded mixed results regarding the neurodevelopmental function of patients following HSCT. Some studies have shown no declines in neurodevelopmental function post-HSCT [5-8], whereas other studies have shown declines post-HSCT [9-11]. Most of these studies have included both malignant and nonmalignant diseases. Conditioning regimens consisted of both irradiation and no irradiation. Consistently, however, studies have shown that younger age was a factor in decreased long-term neurodevelopmental deficits, especially among those who received radiation as part of their therapy. Long-term evaluation of children less than 3 years of age with leukemia who underwent HSCT showed average intelligence but persistent attention deficits at a median of 12 years post-HSCT [12].

The purpose of our study was to evaluate patients with a single diagnosis (SCID) and analyze their long-term neurodevelopment pre-, 1, 3, and 5 years post-HSCT. All patients received a myeloablative conditioning regimen followed by HSCT with either their haploidentical parent or an unrelated donor.

\section{Materials and Methods}

All patients with SCID were eligible for this study. Longterm follow-up protocols were approved by the Committee on Clinical Investigations (Institutional Review Board of Children's Hospital Los Angeles). Consent was obtained from all of the subjects' parents or legal guardians. None of the parents refused to participate in this study. Between October 1997 and October 2006, we evaluated 24 patients who had a diagnosis of SCID. Sixteen patients survived beyond 1 year post-HSCT and were included in this study. Individual patient characteristics are shown in Table I. A schematic diagram of the patients available for testing at different time points is shown in Fig. 1. All patients received a myeloablative conditioning regimen using Busulfan $(16 \mathrm{mg} / \mathrm{kg})$ and either Cytoxan or Campath $1 \mathrm{H}$. All patients were given total parenteral nutrition pre- and post-HSCT until they were able to take adequate enteral calories. All patients received occupational and physical therapy twice a week. One neuropsychologist performed all of the neurocognitive tests. Pre-HSCT evaluations were performed within 1 month of HSCT. Follow-up exams were performed at 1,3 , and 5 years post-HSCT. Due to scheduling and transportation difficulties, examinations were performed within 3 months of the scheduled date. The Bayley Scales of Infant Development [13] was used for patients between the ages of 1 and 42 months. The Bayley provides scores of mental development (MDI) and psychomotor development (PDI). Patients $>42$ months of age received the age-appropriate version of the Wechsler Intelligence Scales (WPPSI) [14]. The WPPSI provides scores of overall cognitive function as well as verbal and performance skills. The unavoidable switch in test instruments may or may not have caused bias in either increasing or decreasing the patient's test scores. Patients also received the validated Vineland Adaptive Scales of Behavior (VABS) [15], which provides scores of socialization and adaptive behavior.

\section{Statistics}

Results are reported as mean $\pm \mathrm{SD}$ or median (min-max). Within group, comparisons between test scores pre- and 1 year post-HSCT were made using paired $t$ tests. Statistical analysis of test scores pre- and 1 year and 3 years postHSCT was done using repeated measures analysis of variance with post hoc, within-subject contrasts between pre- vs. 1 year post-HSCT, and pre- vs. 3 years post-HSCT. Pre-, 1 year, and 5 years post-HSCT scores were only reported descriptively since there were not enough numbers of patients for statistical analysis to be performed. Twosample $t$ tests were used to compare change in scores between subgroups of the patients who (1) were transplanted before and after 8 months of age, (2) had a history of severe infections prior to transplantation, (3) received more than one transplantation, and (4) length of stay in the hospital. Spearman correlation coefficients were used to examine associations between changes in the Bayley and VABS scores. Analyses were performed using the Statistical Analysis System software (SAS, version 9). All statistical tests were two-sided with $\alpha=0.05$.

\section{Results}

Mental Developmental (MDI)

Sixteen patients received neurodevelopmental testing pre- and 1 year post-HSCT. There was a significant decrease in MDI in these patients from baseline to 1 year post-HSCT $(92.6 \pm 12.7$ vs. $70.8 \pm 21.2, p=0.0001$; Fig. 2). Eleven patients received neurodevelopmental testing 3 years post-HSCT (Fig. 3). Nine patients received the Bayley and two patients received the WPPSI. The MDI of these patients showed a decrease from pre- to 1 year to 3 years post-HSCT $(95.8 \pm 11.1$ vs. $72.6 \pm 23.8$ vs. $71.8 \pm 17.4, p=<0.0001)$. The greatest decrease in MDI occurred between pre- and 1 year post-HSCT $(p=0.0004)$. The subsequent decline between 1 year post and 3 years post-HSCT was not significant $(p=0.8)$. Four patients 
Table I Individual Patient Characteristics

\begin{tabular}{|c|c|c|c|c|c|c|c|}
\hline Patient & $\begin{array}{l}\text { Age at } \\
\text { transplant } \\
\text { (months) }\end{array}$ & $\begin{array}{l}\text { Maternal } \\
\text { engraftment }\end{array}$ & $\begin{array}{l}\text { Diagnosed } \\
\text { at birth }\end{array}$ & $\begin{array}{l}\text { Infectious history } \\
\text { prior to HSCT }\end{array}$ & $\begin{array}{l}\text { Type of transplant } \\
\text { chemoTx }\end{array}$ & $\begin{array}{l}\text { More } \\
\text { than } 1 \\
\text { transplant }\end{array}$ & $\begin{array}{l}\text { Length of time } \\
\text { in hospital (months) }\end{array}$ \\
\hline 1 & 6.5 & $\begin{array}{l}\text { Yes/GVHD } \\
\text { at birth }\end{array}$ & No & Minor infection & $\begin{array}{l}\text { Allo/haplo/BM } \\
\mathrm{Bu} / \mathrm{Cy}\end{array}$ & No & 2 \\
\hline 2 & 9 & No & No & PCP, RSV pneumonia & $\begin{array}{l}\mathrm{Bu} / \mathrm{Cy} \\
1 \mathrm{MUD}\end{array}$ & No & 6 \\
\hline 3 & 3.3 & No & Yes & Minor infection & $\begin{array}{l}\text { Allo/haplo/BM } \\
\mathrm{Bu} / \mathrm{Cy}\end{array}$ & No & 8.3 \\
\hline 4 & 11.8 & $\begin{array}{l}\text { Yes/GVHD } \\
\text { at birth }\end{array}$ & No & $\begin{array}{l}\text { Bacterial pneumonia, } \\
\text { intubated ARDS }\end{array}$ & $\begin{array}{l}2 \text { Allo/haplo/BM } \\
\mathrm{Bu} / \mathrm{Cy}\end{array}$ & Yes & 4.7 \\
\hline 5 & 14 & $\begin{array}{l}\text { Yes, GVHD } \\
\text { at birth }\end{array}$ & No & Minor infection & $\begin{array}{l}\text { Allo/haplo/BM } \\
\mathrm{Bu} / \mathrm{Cy}\end{array}$ & No & 3.8 \\
\hline 6 & 6.5 & $\begin{array}{l}\text { Yes/GVHD } \\
\text { at birth }\end{array}$ & No & $\begin{array}{l}\text { PCP, Mechanical } \\
\text { ventilation }\end{array}$ & $\begin{array}{l}\text { Allo/haplo/PBSC } \\
\text { Bu/Campath }\end{array}$ & No & 4.8 \\
\hline 7 & 2.5 & No & Yes & Minor infection & $\begin{array}{l}\text { Allo/haplo/PBSC } \\
\text { Bu/Campath } \\
\text { 1st-UCBT Bu/Cy } \\
\text { 2nd-TBI/Flu/ } \Delta \text { TG }\end{array}$ & Yes & 8.5 \\
\hline 8 & 4.5 & $\begin{array}{l}\text { Yes/GVHD } \\
\text { at birth }\end{array}$ & No & $\begin{array}{l}\text { PCP, recurrent fungal } \\
\text { infection, candida }\end{array}$ & $\begin{array}{l}\text { Allo/haplo/BM } \\
\mathrm{Bu} / \mathrm{Cy}\end{array}$ & No & $\begin{array}{l}16.8 \text { (discharge } \\
\text { delayed } \\
\text { awaiting } \\
\text { medical foster } \\
\text { care placement, } \\
\text { issues }\end{array}$ \\
\hline 9 & 2.5 & $\begin{array}{l}\text { Yes/GVHD } \\
\text { at birth }\end{array}$ & Yes & Minor infection only & $\begin{array}{l}\text { Allo/haplo/BM } \\
\text { Bu/Campath }\end{array}$ & No & 6.9 \\
\hline 10 & 6 & No & No & $\begin{array}{l}\text { Omenn's syndrome, } \\
\text { chronic otitis } \\
\text { media/ mastoiditis }\end{array}$ & $\begin{array}{l}\text { Allo/haplo/PBSC } \\
\text { Bu/Cy } \\
\text { MUD BM } \\
\text { Bu/Flu/rATG }\end{array}$ & Yes & 26.4 \\
\hline 11 & 9 & $\begin{array}{l}\text { Yes/ GVHD } \\
\text { at birth }\end{array}$ & No & $\begin{array}{l}\text { Atypical pneumonia, } \\
\text { Candida }\end{array}$ & $\begin{array}{l}\text { Allo/haplo } \\
\mathrm{Bu} / \mathrm{Cy}\end{array}$ & No & 3.8 \\
\hline 12 & 2.5 & No & Yes & Minor infection only & $\begin{array}{l}\text { Allo/haplo/PBSC } \\
\text { Bu/Campath } \\
\text { Haplo/PBSC } \\
\text { Flu/rATG } \\
\text { Bu/Flu/rATG }\end{array}$ & Yes & 7 \\
\hline 13 & 10.5 & $\begin{array}{l}\text { Yes, but no } \\
\text { GVHD } \\
\text { at birth }\end{array}$ & No & PCP-ventilator & $\begin{array}{l}\text { Allo/haplo/PBSC } \\
\text { Bu/Campath }\end{array}$ & No & 6 \\
\hline 14 & 9.2 & $\begin{array}{l}\text { Yes/GVHD } \\
\text { at birth }\end{array}$ & No & $\begin{array}{l}\text { Pseudomonas } \\
\text { pneumonitis } \\
\text { Parainfluenza infxn- } \\
\text { ventilation ARDS }\end{array}$ & $\begin{array}{l}\text { Allo/haplo/PBSC } \\
\text { Bu/Campath }\end{array}$ & No & 11.7 \\
\hline 15 & 6 & No & No & $\begin{array}{l}\text { Seborrheic dermatitis, } \\
\text { (Omenn's syndrome) }\end{array}$ & $\begin{array}{r}\mathrm{MUD} / \mathrm{BM} / \mathrm{Bu} / \\
\mathrm{Cy} / \mathrm{Flu} / \mathrm{ATG}\end{array}$ & No & 4.6 \\
\hline 16 & 11.2 & No & No & $\begin{array}{l}\text { Chronic diarrhea, } \\
\text { failure to thrive., } \\
\text { pseudomonas } \\
\text { pneumonia }\end{array}$ & $\begin{array}{l}\text { Unrelated cord } \\
\text { blood, Bu/Cy/ } \\
\text { Flu/ATG }\end{array}$ & No & 13.6 \\
\hline
\end{tabular}

$B M$ bone marrow, $B u$ Busulfan, $C y$ Cytoxan, PBSC peripheral blood stem cell, $T B I$ total body irradiation, Flu fludarabine, $A T G$ antithymocyte globulin, Allo allogeneic, Haplo haploidentical, MUD matched unrelated donor, UCBT unrelated cord blood donor, GVHD graft versus host disease, $P C P$ pneumocystis carinii pneumonia, $R S V$ respiratory syncitial virus, $A R D S$ acute respiratory distress syndrome 
Patients Demographics

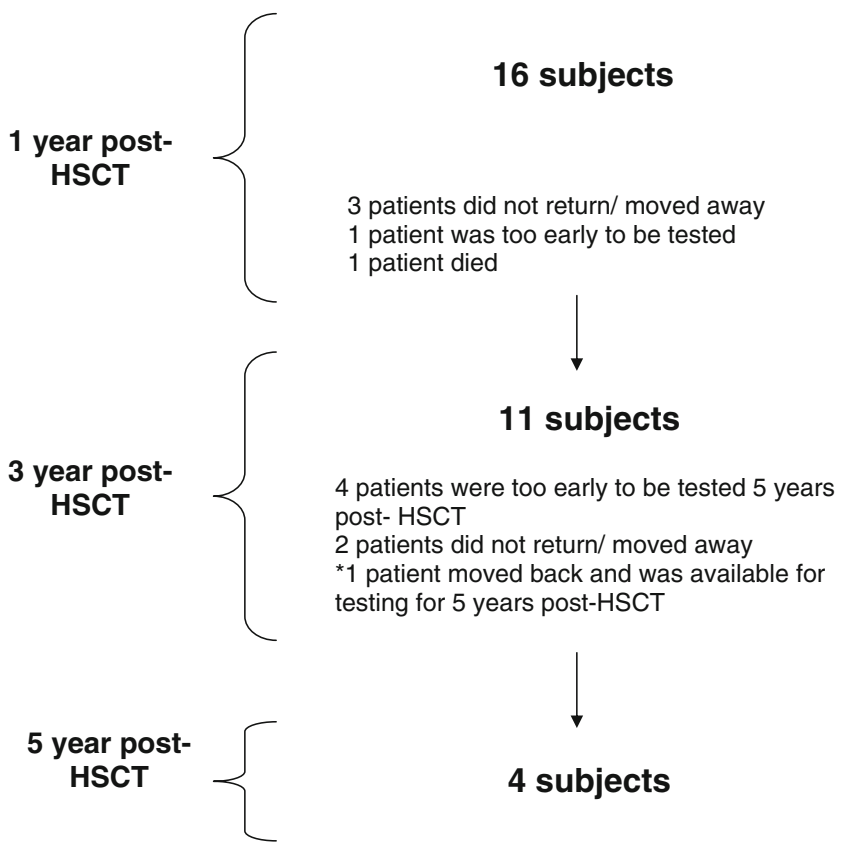

Fig. 1 A schematic diagram of the patients available for testing at different time points

were tested 5 years post-HSCT. One of these patients did not return for their 3-year post-HSCT evaluation, but did return for their 5-year post-HSCT evaluation. The MDI was evaluated using the Bayley pre- and 1 year postHSCT and the WPPSI at 5 years post-HSCT. There was no significant decrease in scores over time [89.5 (pre-HSCT) and 87.5 ( 5 years post-HSCT), $p=0.63$ ]. We do not know what the effect of changing test instruments is on this population.

MDI scores were also analyzed to determine if there was (1) an impact of younger age at transplantation, (2) an impact of having severe infections prior to transplantation, (3) having more than one transplant, and (4) length of stay.

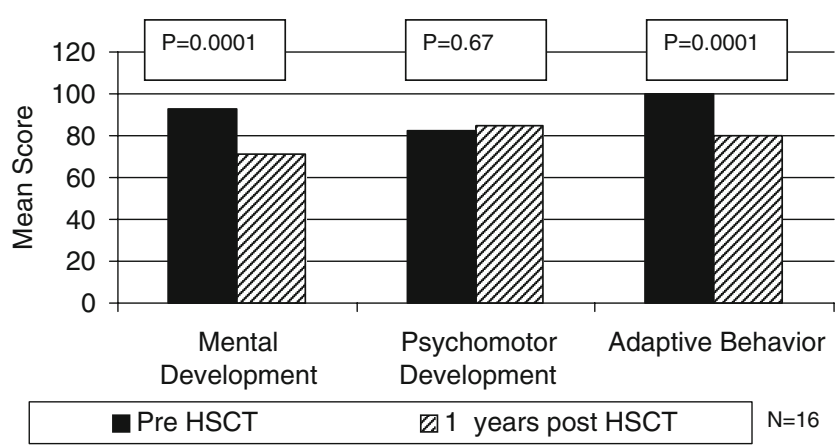

Fig. 2 Mental development scores, psychomotor development scores, and adaptive behavior scores of SCID patients pre- and 1 year post-HSCT

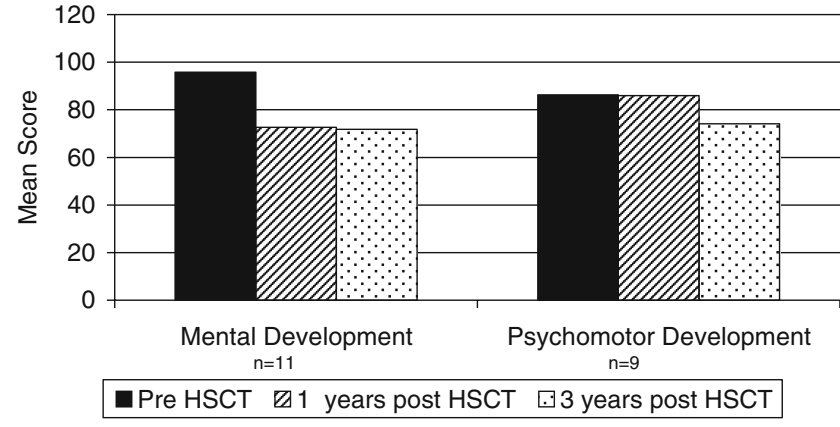

Fig. 3 Mental development scores and psychomotor development scores of SCID patients pre-, 1 year, and 3 years HSCT

The MDI scores pre- and 1 year post-HSCT for these different variables are shown in Table II. With the small numbers in the individual test groups, we could not detect whether there was a difference between the different test groups.

The raw scores for tests of MDI were also analyzed (Fig. 4a). The median raw scores for MDI increased slowly over time: Pre-HSCT MDI scores were 64 (2491) vs. 1 year post- HSCT scores 106 (89-151). Nine patients received the Bayley at 3 years post-HSCT. The median raw score for their MDI was 142 (114-158). Since the test content and scoring vary for different tests, the raw scores for those patients receiving the WPPSI were not evaluated.

Table II Mental Development Scores of Patients Based on Age, Serious Infection, Number of Transplants and Length of Stay (mean \pm SD)

\begin{tabular}{|c|c|c|c|c|}
\hline Factor & & Number & $\begin{array}{l}\text { Mean mental } \\
\text { development score } \\
\text { (pre-HSCT vs. } \\
1 \text { year post-HSCT) }\end{array}$ & $\begin{array}{l}P \text { value } \\
\text { for change }\end{array}$ \\
\hline \multirow[t]{2}{*}{ Age } & $<8$ months & 9 & $\begin{array}{l}92.3 \pm 13.0 \\
68.1 \pm 19.5\end{array}$ & 0.0016 \\
\hline & $>8$ months & 7 & $\begin{array}{l}92.9 \pm 13.4 \\
74.3 \pm 24.4\end{array}$ & 0.0088 \\
\hline \multirow[t]{2}{*}{$\begin{array}{l}\text { Serious } \\
\text { infections }\end{array}$} & Yes & 13 & $\begin{array}{l}91.1 \pm 13.5 \\
70.0 \pm 21.7\end{array}$ & 0.0002 \\
\hline & No & 3 & $\begin{array}{l}99.0 \pm 6.2 \\
74.3 \pm 23.4\end{array}$ & 0.13 \\
\hline \multirow[t]{2}{*}{$\begin{array}{l}\text { No. of } \\
\text { Transplants }\end{array}$} & 1 & 13 & $\begin{array}{l}92.8 \pm 13.7 \\
73.5 \pm 21.7\end{array}$ & 0.0004 \\
\hline & $>1$ & 3 & $\begin{array}{c}91.7 \pm 9.5 \\
59.0 \pm 17.3\end{array}$ & 0.033 \\
\hline \multirow[t]{2}{*}{ Length of stay } & $<180$ days & 8 & $\begin{array}{l}97.3 \pm 11.6 \\
79.4 \pm 22.6\end{array}$ & 0.012 \\
\hline & $>180$ days & 8 & $\begin{array}{l}87.9 \pm 12.8 \\
62.3 \pm 16.9\end{array}$ & 0.0009 \\
\hline
\end{tabular}



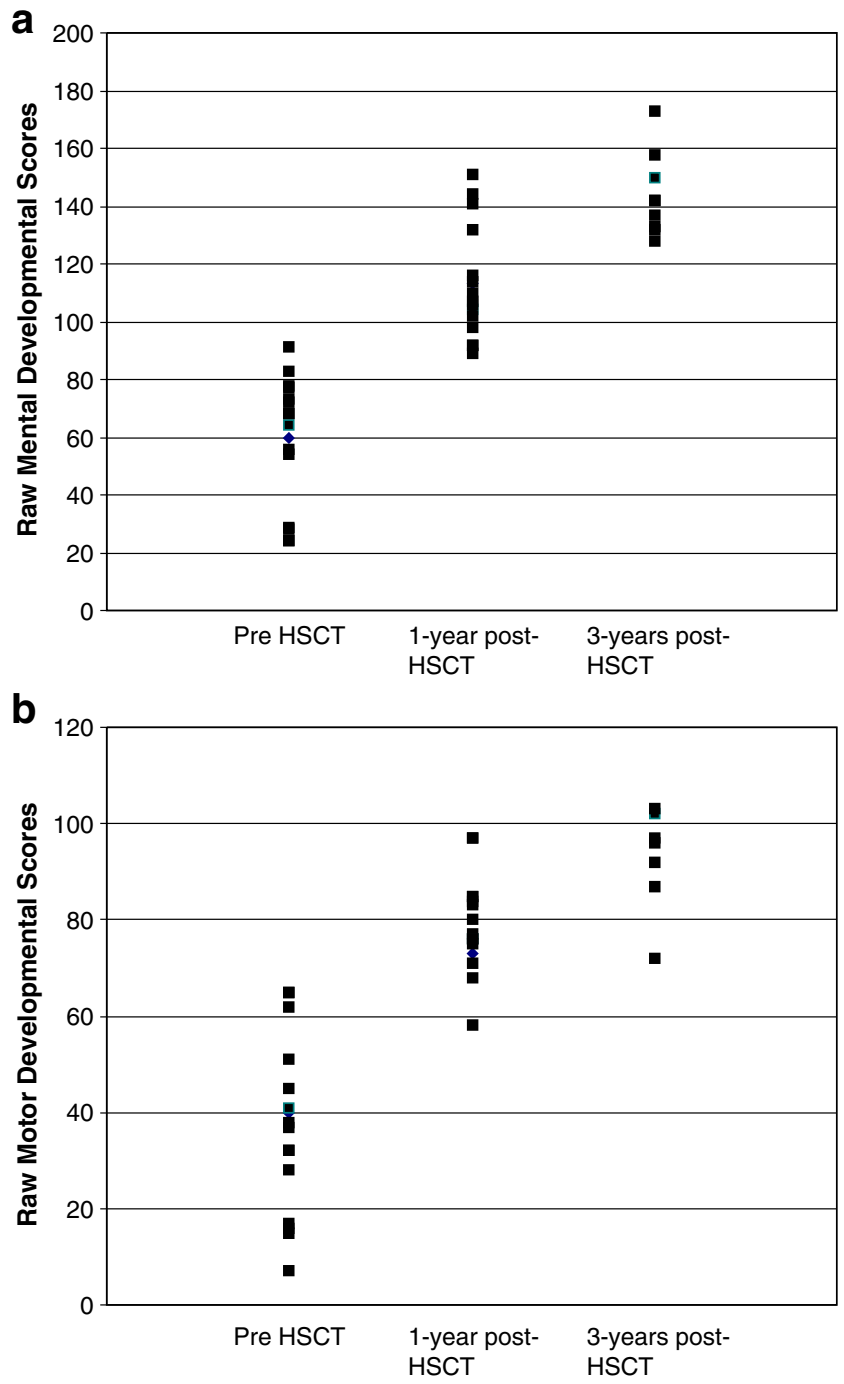

Fig. 4 a Raw scores of mental development pre-, 1 year, and 3 years post-HSCT. b Raw scores of psychomotor development pre-, 1 year, and 3 years post-HSCT

Psychomotor Development (PDI)

There was no significant decrease in PDI during the first year post-HSCT $(82.4 \pm 18.8$ vs. $84.8 \pm 23.0, p=0.69$; Fig. 2). Nine patients also received the Bayley at 3 years post-HSCT. There was a significant decline in PDI scores from pre- to 1 year to 3 years post-HSCT $(86.3 \pm 17.4$ vs. $86.0 \pm 19.7$ vs. $74.1 \pm 15.6, p=0.05)$. The decline from preHSCT to 1 year post-HSCT was not significant $(p=0.96)$; however, the subsequent decline from 1 year post to 3 years post-HSCT was significant $(p=0.008)$. There were no PDI scores at 5 years post-HSCT.

Similar to the MDI scores, the median raw scores for PDI also increased over time. Pre-HSCT PDI scores were 37 (7$65)$ vs. 1-year post-HSCT scores of 77 (32-97). The nine patients who received the Bayley at 3 years post-HSCT had a median raw PDI score of 96 (72-103; Fig. 4b). The remaining patients received the WPPSI at 3 years post-HSCT.

Adaptive Behavior (VABS)

The VABS scores also decreased significantly during the first year post-HSCT (99.7 \pm 7.0 vs. $81.9 \pm 10.1, p=<0.0001$, $n=11)$. Raw scores for the VABS were also analyzed. Mean raw scores increased from $48(12-82)$ pre-HSCT to 110 (77-149). Unlike the MDI and the PDI, there was a significant correlation between age at the time of transplant and change in adaptive living scores from pre- to 1 year post-HSCT. Children who were $<8$ months of age had a decrease in their VABS scores from $103.0 \pm 3.7$ to $77.2 \pm 4.2$, whereas those who were $>8$ months had a significantly smaller decrease from $97.0 \pm 8.2$ to $85.8 \pm 12.3(p=0.023)$. Based on Spearman correlation coefficients, changes in the VABS scores were independent of changes in the MDI $\left(r_{\mathrm{s}}=\right.$ $17, p=0.61)$ and the PDI $\left(r_{\mathrm{s}}=0.24, p=0.47\right)$.

\section{Discussion}

SCID is a life-threatening genetic disease that may be cured by the use of HSCT from a related or unrelated donor. Most children are diagnosed after presenting with an opportunistic infection. Many of these children have failure to thrive and chronic diarrhea. Others have muscle wasting from decreased nutrition. There have been several studies looking at the neurodevelopmental function of children undergoing HSCT. The largest of these studies examined the neurodevelopmental function of 268 patients who underwent HSCT. Although the majority of these patients had a malignant diagnosis, most had minimal risk of longterm neurodevelopmental delays. There were subgroups of patients that were at risk, including those who received total body irradiation (TBI), those receiving unrelated transplants, and those with graft vs. host disease [16].

Our study shows that SCID patients have decreased mental development 1 year post-HSCT, followed by a stabilization in test scores over time. However, when analyzing the raw scores of these patients, there was a slow steady improvement over time. These raw scores showed that patients with SCID acquired new developmental skills, but at a slower rate than their age-matched peers.

There are many possible explanations as to why patients with SCID had a mental development that was slower than their age-matched peers. First, there have been many studies stating that chemotherapy/HSCT causes neurodevelopmental deficits in young children [9-11]. These studies were based mostly on patients who received chemotherapy for leukemia. Leukemia patients receive much more intensive therapy to their craniospinal axis (intrathecal 
chemotherapy and possibly cranial irradiation), whereas SCID patients do not receive the same intensity of chemotherapy. We do not know the impact of chemotherapy on the neurodevelopmental function of patients with SCID since all of our patients received a myeloablative transplant. Second, most patients with SCID are diagnosed early in life after a severe infection. Many have been hospitalized for an extensive period of time. Even after they leave the hospital, they remain immunosuppressed and are therefore socially isolated from other children for a prolonged period. Many patients have no other siblings and are not able to see and interact with any children. These factors lead to a lack of exposure to developmental stimuli. These factors seem a likely cause as to why there are significant decreases in development for the first 3 years post-HSCT. It is encouraging to see that those patients, whose immunosuppression has decreased over time, are able to lead more normal lifestyles. There were four patients who were tested 5 years post-HSCT. These patients have returned to school and have minimal immunosuppression. These four patients have overall development scores that are comparable to their test scores prior to HSCT.

Our study does not appear to show an impact on motor development the first year post-HSCT, but there is a decrease in the overall motor development at 3 years postHSCT. A possible explanation for this is that while in the hospital, patients receive physical therapy regularly. While home, intensive physical therapy may not occur regularly. Since these patients remain immunosuppressed, they are not able to join playgroups and gym classes as other normal toddlers do. Therefore, the psychomotor development scores may decline until they have the ability to increase social interactions.

Adaptive behavior scores show that the younger children have worse adaptive function than those who were transplanted $>8$ months of age. Some of our patients were diagnosed shortly after birth, since there had been a previously affected child in the family. Unlike many of the children who were diagnosed and transplanted later in life, these children were hospitalized at birth and remained in protective isolation until they were discharged home. Being in the hospital at such an early age and not being able to interact with outside stimulation is the most likely cause of decreased adaptive function in our younger children. We do not perform long-term adaptive behavioral studied on these children, so we do not know if the adaptive function improves once these children are discharged from the hospital or not.

The majority of studies addressing the long-term neurodevelopmental function post-HSCT have focused on patients with a variety of diseases (malignant and nonmalignant). The major limitation of this study as well as other studies of neurocognitive outcomes post-pediatric
HSCT is the small sample size. SCID is a very rare disease, so the numbers of patients in this study is small, which is unavoidable. In addition, the presenting symptoms of patients and their outcomes vary considerably. The strength of this study is that all patients had the same diagnosis, SCID. None of these patients had received prior chemotherapy, unlike patients have who received HSCT for a malignant disease. The second strength of this study is that all patients received a Busulfan-containing conditioning regimen. There was not a mixture of both TBI and nonTBI-based conditioning regimens as is seen in most studies of this nature. We do not know the outcomes of patients who did not receive a chemotherapy conditioning regimen prior to HSCT. However, due to the social isolation and prolonged immunosuppression that occurs with any transplant for SCID, it is possible that the neurocognitive function of all recipients of HSCT for SCID will have some developmental delays until they are able to increase their social interactions. Long-term studies should focus on comparing those who did and did not receive a chemotherapy conditioning regimen to determine the impact on chemotherapy as well as social isolation.

This study highlights the problems that clinicians and parents will need to be aware of long term. It will be important to try to integrate these children with normal activities as soon as medically eligible. As these children approach school, clinicians should be ready to work with the school in implementing interventions as needed.

Acknowledgments This work was supported in part by the National Institute of Health NCRR General Clinical Research Center (GCRC) grant MO1 RR00043 and was performed at the GCRC at Children's Hospital Los Angeles. Computational assistance was provided by the National institutes of Health NCRR GCRC MO1 RR00043, CDMAS Project and was performed at the GCRC at Children's Hospital Los Angeles. The authors would like to thank the patients and their families for the participation in this study and the nursing staff of the Children's Hospital Los Angeles Bone Marrow Transplant Unit for their tireless commitment to these patients.

\section{References}

1. Bortin MM, Rimm AA. Severe combined immunodeficiency disease: characterization of the disease and results of transplantation. JAMA 1977;238:591-600. doi:10.1001/jama.238.7.591.

2. Fischer A, Le Deist F, Hacein-Bey-Abina S, et al. Severe combined immunodeficiency. A model disease for molecular immunology and therapy. Immunol Rev 2005;203:98-109. doi:10.1111/j.0105-2896.2005.00223.x.

3. Meuwissen HJ, Pollara B, Pickering RG. Combined immunodeficiency disease associated with adenosine deaminase deficiency. J Pediatr 1975;86:169-81. doi:10.1016/S0022-3476(75) 80463-X. 
4. Gatti RA, Meuwissen HJ, Allen HD, et al. Immunological reconstitution of sex-linked lymphopenic immunological deficiency. Lancet 1968;2:1366-9. doi:10.1016/S0140-6736(68)92673-1.

5. Simms S, Kazak AE, Gannon T, Goldwein J, Bunin N. Neuropsychological outcome of children undergoing bone marrow transplantation. Bone Marrow Transplant 1998;22:181-4. doi:10.1038/sj.bmt.1701295.

6. Phipps S, Brenner M, Heslop H, Kranec R, Jayawardene D, Mulhern R. Psychological effects of bone marrow transplantation on children and adolescents: preliminary report of a longitudinal study. Bone Marrow Transplant 1995;15:829-35.

7. Simms S, Kazak AE, Golomb V, Goldwein J, Bunin N. Cognitive, behavioral and social outcome in survivors of childhood stem cell transplantation. J Pediatr Hematol Oncol 2002;25:5-7.

8. Phipps S, Dunavant M, Srivastava DK, Bowman L, Mulhern R. Cognitive and academic functioning in survivors of pediatric bone marrow transplantation. J Clin Oncol 2000;18:1004-11.

9. Cool VA. Long-term neuropsychological risks in pediatric bone marrow transplant: what do we know? Bone Marrow Transplant 1996;Suppl 3(18):S45-9.

10. Smedler AC, Nilsson C, Bolme P. Total body irradiation: a neuropsychological risk factor in pediatric bone marrow transplant recipients. Acta Paediatr 1995;84:325-30. doi:10.1111/j.16512227.1995.tb13637.x.

11. Kramer JH, Crittendon MR, DeSantes K, Cowan MJ. Cognitive and adaptive behavior 1and 3 years following bone marrow transplantation. Bone Marrow Transplant 1997;19:607-13. doi:10.1038/sj.bmt.1700699.

12. Perkins JL, Kunin-Batson AS, Youngren NM, et al. Long-term follow up of children who underwent hematopoietic cell transplant (HCT) for AML or ALL at less than 3 years of age. Pediatr Blood Cancer 2007;49:958-63. doi:10.1002/pbc. 21207.

13. Bayley N. Bayley scales of infant development-2nd. San Antonio: The Psychological Corporation; 1993.

14. Wechsler D. The Wechsler Preschool and Primary Scale of Intelligence — revised. San Antonio: The Psychological Corporation; 1989.

15. Sparrow SS, Balla DA, Cicchetti DV. Vineland Adaptive Behavior Scales. American Guidance Service: Circles Pines, Minnesota; 1984.

16. Phipps S, Rai SN, Leung WH, et al. Congnitive and academic consequences of stem-cell transplantation in children. J Clin Oncol 2008;26:2027-33. doi:10.1200/JCO.2007.13.6135. 